\title{
Factor Structure for Organizational Police Stress Questionnaire (PSQ-Org) in Bangladeshi Culture
}

\author{
Mahmudul Hasan Sagar ${ }^{*}$, A.K.M. Rezaul Karim, Naima Nigar \\ Department of Psychology, University of Dhaka, Dhaka-1000, Bangladesh \\ *Corresponding Author: mmhasansagar@yahoo.com
}

Copyright $@ 2014$ Horizon Research Publishing All rights reserved.

\begin{abstract}
The importance of the organizational police stress research has increased in recent times. One important measure of organizational police stress is the Organizational Police Stress Questionnaire (PSQ-Org; was McCreary \& Thompson, 2006). The purpose of the present study was to translate the measure into Bangla and validate in Bangladeshi Culture. A total of 210 police officers participated in this survey. Exploratory factor analysis (EFA) of the data from 160 participants (who provided complete responses) identified four factor structures for PSQ-Org with 14 items. The four factors for PSQ-Org namely 'Poor management and bureaucracy', 'Lack of manpower and resources', 'Feelings of excessive duty and being supervised' and 'Lack of leisure time and negative evaluations' together explained $55.14 \%$ of the total variance. The PSQ-Org showed moderate to high internal consistency (Cronbach's a $=.80$ for PSQ-Org; and .57 to .66 for its factors) strong translation validity and convergent validity. Thus, the Bangla version PSQ-Org appears to be a valid and reliable measure that can be used for further research in Bangladesh.
\end{abstract}

Keywords Factor Structure, Organizational Police Stress, Bangladeshi Culture

\section{Introduction}

At present, Psychologist is giving much attention to the study of stress in police. Police is a service organization having highest responsibility to maintain order and peace in any country by reducing criminal activities in the society.

Policing is considered one of the most stressful occupations, exposing staff to occupational, organizational, and personal stressors (Alexander, 1999; Paton \& Violanti, 1999; Anshel, 2000). Work-place stress has received a great deal of attention in psycho-social research (Cooper, Dewe, \& O'Driscoll, 2001). Significant research findings have documented that prolonged stress has negative effects on individual health (Mohren et al., 2003; Ursin \& Eriksen, 2004) as well as on employees' attitudes towards the organization (Cropanzano, Rupp, \& Byrne, 2003). Gershon
(2000) concurs that working under continuously stressful conditions leads to the dissatisfaction and exhaustion of police officers.

A stress can be said organizational in the sense that the stressors are associated with the organization and culture within which polices are performing their job. (Symonds, 1970; McCreary \& Thompson, 2006). Organizational stress is a broadly defined concept that includes certain characteristics of the organization and behaviors of its employees that may create stress for the employees. Bureaucratic processes, perceived lack of support from the community and leaders, and lack of promotion opportunities in the organization have been emphasized as organizational stressors (Stinchcomb, 2004). Toch, Bailey and Floss (2002) noted as features of organizational stress inconsistent discipline procedures and management style, and lack of administrative support. The policies and practices that law enforcement organizations require their employees to follow when doing their job in the field or in the workplace are considered potential organizational stress factors (Ellison, 2004). In addition, the relationship between an organization and the media is identified as a common organizational stressor (Violanti \& Aron, 1995). Excessive workload and administrative duties, characteristics of the bureaucratic nature of law enforcement agencies, can create a stressful work environment (Violanti \& Aron, 1995). Favoritism also has been examined by many scholars as an important organizational stress that affects the morale and wellbeing of employees (Klockars, Ivkovic \& Haberfeld 2006).

In the organizational setting, aversive stimuli may arise from the structural characteristics of, or adverse experiences in the workplace that upset the normal operating environment a person is accustomed to, thus leading to negative behavioral, physiological and psychological responses (e.g., Gershon et al., 2009). Inside a police department, aversive stimuli may emanate from the organization's design (Bureaucratic and hierarchical), as well as life within that structure. This interaction between the person and their environment (Interactive theory) has its roots in the physical sciences, specifically physics. In the physical sciences, stress is defined as “...the distortion produced by an external force placing strain on an object. 
The amount of damage that results will depend on both the strength of the force and the ability of the object to withstand it" (Stinchcomb, 2004, p. 261). In the policing context, the distortion that results is reflected in the variance in police performance and adjustment.

The implication is that stress emanates from the conditions that are imposed on police officers under circumstances beyond their control. The job of police officer is often characterized as high demand and low control because of the authoritarian, quasi-military structure and bureaucratic nature, which fails to recognize the autonomy and decision latitude of individual officers (Brown, 1996; Potts, 1982). These workplace constraints reduce the amount of control a police officer has over many aspects of career success and daily life. Police departments are bureaucracies with rigid hierarchical power (Control) structures, where the greatest degree of control resides at the top of the organization. Therefore, employees at the lowest level of the organization who have the highest demands and the least amount of control may suffer from the highest levels stress (e.g., Morash, Haar \& Kwak, 2009). Determining the organizational stress inside the police agency requires a valid and objective instrument to measure organizational stress of policing.

For measuring such a broad concept standardized measures have been developed in western country like Canada. But in Bangladesh there is no such a measure. Since the police profession has become an important issue in Bangladesh and the service of the police is very essential to keep the country safe from different destructive activities. It is also very easy to assume that the quality oriented and the spontaneous service of the police will be hampered by the organizational stress of police. So it is very important to study the organizational police stress of Bangladeshi police. In order to achieve this goal, a psychometrically sound (i.e. reliable, valid and objective) Bangla version measure of organizational police stress is needed. If such a measure can be developed within the socio-cultural context of Bangladesh, it will be helpful to achieve theoretical as well as practical purposes.

\section{Method}

\subsection{The Sample}

210 police officers from 28 police stations in Dhaka city conveniently taken as the sample for the study. Among them 160 (Male $=145$, Female $=5, \&$ Unknown=10) police officers provided complete responses to the questionnaires used in this study. The rate of complete response was $76.19 \%$. The age of the police officers ranged from 19 to 58 years with a mean of 33.48 and an SD of 8.06. The monthly income of the participants ranged from Taka 5,000.00 to 50,000.00 with a mean of 19,756.64 and SD of 10548.34. The job duration ranged from 1 to 22 years with a mean of 6.78 and an SD of
7.11. The proportions of the married and unmarried respondents were $57.5 \%$ and $38.8 \%$ respectively. The marital status of $3.8 \%$ participants was unknown. Among the participants $22.5 \%$ were Constable, $3.1 \%$ were Nayek, $18.1 \%$ were Assistant sub-inspector (ASI), 48.1\% were Sub-inspector (SI), $6.3 \%$ were Inspector and $1.9 \%$ were SP.

\subsection{Measures}

\subsubsection{The Organizational Police Stress Questionnaire}

The Organizational Police Stress Questionnaire (PSQ-Org) was developed to measure organizational stress of police officers (McCreary \& Thompson, 2006). It is a 20 -item measure to be rated on a 7-point Likert type scale ranging from 1 (No stress at all) to 7 (A lot of stress). The Cronbach's a for the original PSQ-Org was found to be 92.The corrected item-total correlations for the PSQ-Org ranged from .41 to .73. High levels of content validity and convergent validity were reported for the PSQ-Org(Taylor \& Bennel, 2010). Concurrent validity for the PSQ-Org was demonstrated by the correlations between stress ratings for the PSQ items and ratings on two measures of job satisfaction (McCreary \& Thompson, 2006). The correlation between the Stress and Frequency ratings on the PSQ-Org was .72. The correlations show that the stress and frequency ratings of organizational stressors shared $52 \%$ of their variance (determined by the use $o f r^{2}$ ). These findings indicate that the stress ratings and frequency ratings are intercorrelated (McCreary \& Thompson, 2006).

\subsection{Procedures}

\subsubsection{Translating the PSQ-Org into Bangla}

The PSQ-Org items were first translated into Bangla, called the first draft. It was then given to six judges including two experts in Bangla, two experts in English and two experts in Psychololgy/Psychometrics. Though their native language was Bangla, but being teacher of University or college they had very good command in English. Their task was to judge the accuracy of translation and relevance/suitability of each item for measuring organizational and operational stress of police officers in the socio-cultural context of Bangladesh. Each expert independently rated the translation using a 2-point scale $(0=$ Not correct, $1=$ correct $)$ and the relevance of each item using another 2 -point scale $(0=$ Not relevant, $1=$ Relevant $)$. Following their evaluation, accuracy of the translation was examined by calculating for each item the Accuracy Index (AI=Number of Rating 1/Number of experts; Karim \& Nigar, 2013). The item yielding an $\mathrm{AI}$ of $1(\mathrm{AI}=6 / 6)$ was considered to be correctly and reliably translated (Karim \& Nigar, 2013). All the six experts rated 16 items translation at 1 for PSQ-Org, the AI for each of them becoming 1. The remaining 4 items for PSQ-Org yielded an AI of less than 1. The expert suggested some corrections to the clarity, wording and organization of these items. By reviewing those 
items in the light of their comments and suggestions the accuracy of translation was ensured. The relevance/suitability of the items in Bangladeshi culture was examined by calculating for each item the Relevance Index (RI=Number of Rating at 1/Number of Experts; Karim and Nigar, 2013). The item yielding an RI of 1 or .67 (RI=6/6 or 4/6) was considered to be relevant or suitable. All the six experts rated the relevance of each item at 1 , the RI for them becoming 1. Thus, the second draft of the Bangla version PSQ-Org was finalized to administer on the selected participants.

\subsubsection{Data Acquisition}

Standard data collection procedures were followed in this study. At first, permission from the Dhaka Metropolitan Police (D.M.P) commissioner was taken. Then, this permission letter was shown to the Officer in Charge (OC) of the police stations. For taking consent he or she was briefed about the general purpose of the study and requested to cooperate with the researcher. The OC was also informed that the investigation is purely academic and their responses to the questionnaire would be kept confidential. In conducting the study, the police officers in different ranks were contacted in person. Then the above measures were administered to them requesting to respond to the questionnaires during free time. Prior to answering the questions, police officers were requested to go through the standard instructions given on the questionnaires. They were also asked to record their socio-demographic information (e.g. age, sex, rank, educational qualification, marital status, socio-economic status, etc.). Thus data collection from all the participants was completed in 3 months.

\subsubsection{Data Analyses}

Each participant's responses to the test items were scored according to the scoring principles of the PSQ-Org. Fifty participants left a few PSQ-Org items with missing responses and were therefore excluded from further processing. Data for the remaining 160 participants were fed into computer for factor analysis on IBM SPSS Statistics 20. According to standard textbook authors and researchers, the minimum sample size for factor analysis varies from 100 (e.g., Kline, 1979; Gorsuch, 1983) to 250 (e.g., Cattell, 1978), and there is practice of applying factor analysis even to the data for less than 100 participants (e.g., Widyanto and McMurran, 2004). There is another set of recommendations varying from a minimum SV (subjects-to- variables) ratio of 2:1 (e.g., Guilford, 1956; Kline, 1979) to 10:1 (e.g., Everitt, 1975; Kunce et al., 1975; Nunnally, 1978; Marascuilo and Levin, 1983). The number of participants in this study was about 8 times the number of PSQ-Org items/variables (20). Thus the sample size required for factor analysis was satisfied. However, before carrying out factor analysis we examined the response distributions of all PSQ-Org items and estimated their internal consistency by investigating inter-item correlations and item- total correlations. Then we analyzed the data in Exploratory Factor Analysis (EFA), a method widely used to uncover the underlying structure of a relatively large set of variables (e.g., Gratz and Roemer, 2004; Hawi, 2013; Korkeila et al., 2010; Muris, 2001; Widyanto et al., 2011; Widyanto and McMurran, 2004). We also examined the convergent validity by correlating the PSQ-Org with the PSQ-Org subtests and the reliability by estimating internal consistency (Cronbach $\alpha$ ) of the full test and subtests as well.

\section{Results}

\subsection{Factor Structure of PSQ-Org}

\subsubsection{Item Analysis}

Response distribution of the PSQ-Org items indicated that none of these variables/items were excessively skewed or kurtotic. So, no item was excluded on the basis of the item response distribution. (Kendall \& Stuart, 1958; Karim \& Nigar, 2013). However, the obtained inter-item correlation matrix (R-matrix, not shown) contained 12 negative values and out of 190 inter-item correlation coefficients 133 were significant $(\mathrm{p} \leq .01 ; \mathrm{p} \leq .05)$. The inter-item correlation ranged from -.10 to .59. All the item-total correlations were significant $(\mathrm{p} \leq .01)$ and ranged from .20 to .67 with a mean of .47. In order to disregard the 12 negative inter-item correlations, 6 items were excluded from the original scale. Thus, 14 items were rest for factor analysis. The correlation matrix for these 14 items is given in Table 1 .

The figures in Table 1 indicate that out of 91 inter-item correlations 87 are significant $(p \leq .01 ; p \leq .05)$ which range from .13 to .47 . All the item-total correlations are significant $(\mathrm{p} \leq .01)$ and range from .36 to .60 with a mean of .52

\subsubsection{Factor Analysis}

First, in order to examine whether data were suitable for factor analysis, measures of sampling adequacy were carried out on the 14-item PSQ-Org. The determinant of the R-matrix was 0.048 ( $>0.00001$, Field, 2005), indicating that there was no multicolinearity (very highly correlated variables) or singularity (perfectly correlated variables) problem. The Kaiser- Meyer-Olkin (KMO) measure indicated a value of 0.79 which exceeded the recommended value of .60 (Kaiser, 1970) and Bartlett's test of sphericity indicated a $X^{2}$ value of $466.94(p<0.001)$. All this together supports the factorability of the R- matrix.Data for the 14 PSQ-Org items were therefore subjected to exploratory factor analysis (EFA). Method of principal component (PC) with varimax rotation was used which identified 4 factors.. 
Table 1. Correlation matrix for the 14 item PSQ-Org

\begin{tabular}{|c|c|c|c|c|c|c|c|c|c|c|c|c|c|c|c|}
\hline Item & 3 & 4 & 5 & 6 & 7 & 8 & 9 & 10 & 11 & 12 & 13 & 16 & 18 & 20 & $\begin{array}{c}\text { PSQ- } \\
\text { Org- } \\
\text { Total }\end{array}$ \\
\hline 3 & 1 & & & & & & & & & & & & & & \\
\hline 4 & $.29^{* *}$ & 1 & & & & & & & & & & & & & \\
\hline 5 & .10 & $.42^{* *}$ & 1 & & & & & & & & & & & & \\
\hline 6 & $.18^{*}$ & $.33^{* *}$ & $.42^{* *}$ & 1 & & & & & & & & & & & \\
\hline 7 & $.15^{*}$ & $.28^{* *}$ & $.47^{* *}$ & $.39^{* *}$ & 1 & & & & & & & & & & \\
\hline 8 & $.31^{* *}$ & $.27^{* *}$ & $.16^{*}$ & .10 & .04 & 1 & & & & & & & & & \\
\hline 9 & .04 & $.25^{* *}$ & $.28^{* *}$ & $.24^{* *}$ & $.31^{* *}$ & $.19^{* *}$ & 1 & & & & & & & & \\
\hline 10 & .05 & $.22^{* *}$ & .09 & $.15^{*}$ & .11 & .08 & $.25^{* *}$ & 1 & & & & & & & \\
\hline 11 & $.34^{* *}$ & $.31^{* *}$ & $.14^{*}$ & $.26^{* *}$ & .12 & $.22^{* *}$ & $.14^{*}$ & $.29^{* *}$ & 1 & & & & & & \\
\hline 12 & .08 & .11 & $.36^{* *}$ & $.24^{* *}$ & $.34^{* *}$ & .01 & $.20^{* *}$ & $.22^{* *}$ & $.23^{* *}$ & 1 & & & & & \\
\hline 13 & $.13^{*}$ & $.16^{*}$ & $.28^{* *}$ & $.26^{* *}$ & $.33^{* *}$ & .10 & $.32^{* *}$ & $.21^{* *}$ & $.25^{* *}$ & $.24^{* *}$ & 1 & & & & \\
\hline 16 & $.25^{* *}$ & $.24^{* *}$ & $.31^{* *}$ & .13 & $.32^{* *}$ & $.13^{*}$ & $.20^{* *}$ & $.32^{* *}$ & $.25^{* *}$ & $.31^{* *}$ & $.26^{* *}$ & 1 & & & \\
\hline 18 & $.16^{*}$ & $.29^{* *}$ & $.14^{*}$ & .05 & $.14^{*}$ & .05 & .12 & $.21^{* *}$ & $.21^{* *}$ & $.16^{*}$ & $.22^{* *}$ & $.37^{* *}$ & 1 & & \\
\hline 20 & $.19^{* *}$ & $.18^{*}$ & $.21^{* *}$ & $.38^{* *}$ & $.18^{*}$ & .13 & $.22^{* *}$ & $.21^{* *}$ & $.30^{* *}$ & $.16^{*}$ & $.46^{* *}$ & .12 & $.19^{* *}$ & 1 & \\
\hline $\begin{array}{l}\text { PSQ-Org- } \\
\text { Total }\end{array}$ & $.44^{* *}$ & $.59^{* *}$ & $.60^{* *}$ & $.57^{* *}$ & $.58^{* *}$ & $.36^{* *}$ & $.52^{* *}$ & $.46^{* *}$ & $.55^{* *}$ & $.51^{* * *}$ & $.59^{* *}$ & $.55^{* *}$ & $.45^{* *}$ & $.55^{*}$ & 1 \\
\hline
\end{tabular}

$* \mathrm{p} \leq 0.05$, (one-tailed) $* * \mathrm{p} \leq 0.01$, (one-tailed)

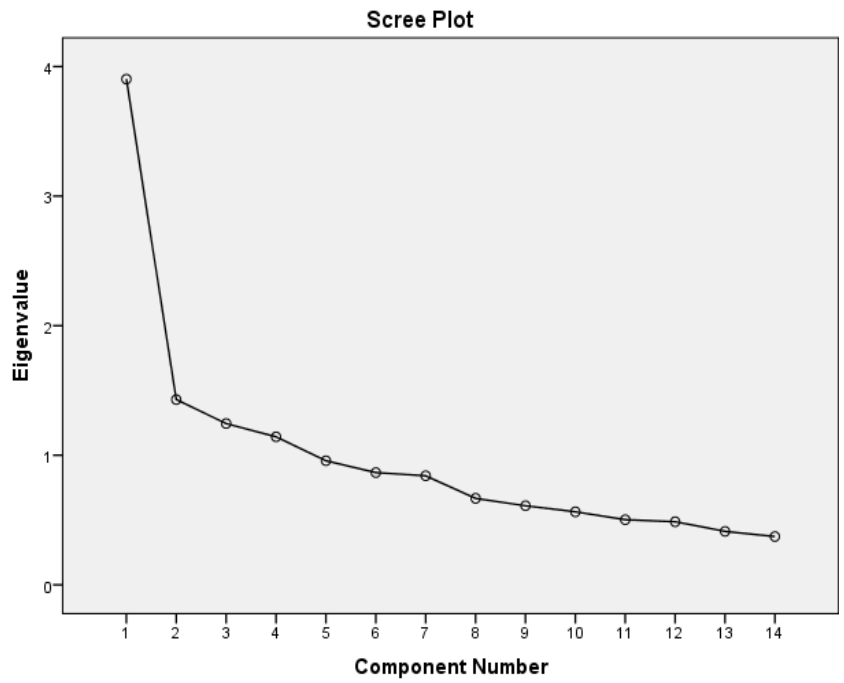

Figure 1. The scree plot generated in EFA for 14 items.

Consistently inspection of the scree plot (Figure 1, cattel, 1966) also revealed a clear break after the 4 th component leading us to retain 4 components. These four factors, which were rotated to position of maximum orthogonality in six iterations, explained together $55.14 \%$ of the total variance (Table 2).

Table 2 shown that Factor 1 accounts for $16.71 \%$ of the variance, Factor 2 accounts for $12.96 \%$ of the variance, Factor 3 accounts for $12.76 \%$ of the variance, and Factor 4 accounts for $12.71 \%$ of the variance. Before labeling the factors we identified three pairs of cross-loadings between the factors. Specifically, item 04 was cross loaded on Factor 1 and Factor 3 with the loadings of .415 and .577 respectively; item 6 was cross-loaded on Factor 1 and Factor 2 with the loadings of .566 and .437 respectively; and item 11 was cross-loaded on Factor 2 and Factor 3 with the loadings of .411 and .485 respectively. We grouped both item 04 and item 11 under Factor 3, the factor of their greater loadings and best conceptual fit; and item 6 under Factor 2, the factor of its smaller loading but best conceptual fit. Thus Factor 1 comprises items 5, 7, 9, and 12 which we termed as 'Poor management and bureaucracy', Factor 2 comprises items 6, 13 and 20 which we termed as 'Lack of manpower and resources', Factor 3 comprises items 3, 4, 8, and 11 which we termed as 'Feelings of excessive duty and being supervised', and Factor 4 comprises items 10, 16 and 18 which we termed as 'Lack of leisure time and negative evaluations'.

\subsection{Validity}

\subsubsection{Translation Validity}

Translation validity of the measure was examined in two ways as below.

\subsubsection{Content Validity}

The content validity of the PSQ-Org was assessed in the present study. The Accuracy Index (AI) and Relevance Index (RI) were set as the criteria. The values of both AI and $\mathrm{RI}$ revealed that the measure has content validity. (For details see method section). 
Table 2. Rotated factor matrix for a reduced set of PSQ-Org item

\begin{tabular}{|c|c|c|c|c|c|}
\hline \multirow{2}{*}{\multicolumn{2}{|c|}{ PSQ-Org items }} & \multicolumn{4}{|c|}{ Factor loadings } \\
\hline & & F1 & $\mathrm{F} 2$ & F3 & F4 \\
\hline Item 05 & Constant changes in policy/ legislation & .803 & & & \\
\hline Item 07 & Bureaucratic red tape & .769 & & & \\
\hline Item 09 & Lack of training on new equipment & .408 & & & \\
\hline Item 12 & Inconsistent leadership style & .505 & & & \\
\hline Item 06 & Staff shortages & $(.566)$ & .437 & & \\
\hline Item 13 & Lack of resources & & .674 & & \\
\hline Item 20 & Inadequate equipment & & .822 & & \\
\hline Item 03 & $\begin{array}{c}\text { Feeling like you always have to prove yourself to the } \\
\text { organization }\end{array}$ & & & .731 & \\
\hline Item 04 & Excessive administrative duties & $(.415)$ & & .577 & \\
\hline Item 08 & Too much computer work & & & .713 & \\
\hline Item 11 & Dealing with supervisors & & $(.411)$ & .485 & \\
\hline Item 10 & Perceived pressure to volunteer free time & & & & .593 \\
\hline Item 16 & $\begin{array}{l}\text { Leaders over-emphasize the negatives (e.g. } \\
\text { supervisor evaluations, public complaints) }\end{array}$ & & & & .714 \\
\hline Item 18 & Dealing the court system & & & & .697 \\
\hline Eigen value & & 3.90 & 1.43 & 1.24 & 1.14 \\
\hline Variance explained & & $16.71 \%$ & $12.96 \%$ & $12.75 \%$ & $12.72 \%$ \\
\hline Cronbach's $\alpha$ & & .66 & .64 & .62 & .57 \\
\hline
\end{tabular}

Note. $\mathrm{N}=160$

Factor loadings $<.40$ were suppressed.

Items corresponding to the parenthesized loadings did not conceptually fit with the corresponding factors

Extraction method: principle component analysis

Rotation method: Varimax with Kaiser normalization

\subsubsection{Face Validity}

The measure seems to have a good translation of the construct on its face. Face validity of the instrument was further assessed in more meaningful sense as described below:

We added six questions with a 2-point scale (yes- no) at the end of the measure to examine face validity. The questions included whether the questionnaire was readable, logical, clear, comprehensive, answerable and also to the style \& format of the questions were acceptable? Participants gave their responses to these six questions. The percentages of yes responses to readability, logic, clearness, comprehensiveness, answerability and style and format were $95.6 \%, 90.6 \%, 88.1 \%, 85 \%, 66.9 \%$, and $93.1 \%$.Thus the PSQ-Org has face validity.

\subsubsection{Convergent Validity}

Convergent validity of the Bangla version PSQ-Org was examined by estimating inter-factor correlations and the factor-total correlations. These are shown in Table 3.

Table 3. Correlation matrix for four PSQ-Org factors and the PSQ-Org

\begin{tabular}{cccccc}
\hline $\begin{array}{c}\text { PSQ-Org/its } \\
\text { factors }\end{array}$ & $\mathrm{F} 1$ & $\mathrm{~F} 2$ & $\mathrm{~F} 3$ & $\mathrm{~F} 4$ & PSQ-Org \\
\hline $\mathrm{F} 1$ & 1 & & & & \\
\hline $\mathrm{F} 2$ & $.46^{* *}$ & 1 & & & \\
\hline $\mathrm{F} 3$ & $.58^{* *}$ & $.53^{* *}$ & 1 & & \\
\hline $\mathrm{F} 4$ & $.42^{* *}$ & $.50^{* *}$ & $.36^{* *}$ & 1 & \\
\hline PSQ-Org & $.87^{* *}$ & $.78^{* *}$ & $.79^{* *}$ & $.62^{* *}$ & 1 \\
\hline
\end{tabular}

Note. $\mathrm{F} 1=$ Poor management and bureaucracy, $\mathrm{F} 2=$ Lack of manpower and resources,

F3= Feelings of excessive duty and being supervised, F4= Lack of leisure time and negative evaluation

$* \mathrm{p} \leq 0.05$, (one-tailed) $\quad * * \mathrm{p} \leq 0.01$, (one-tailed) 
The table indicates that the inter-factor correlations (Pearson's r) were all significant, the coefficients ranging from .36 to .58 . The strongest correlation (.58) was found between F1 (Poor management and bureaucracy) and F3 (Feelings of excessive duty and being supervised) and the weakest (.36) between F3 (Feelings of excessive duty and being supervised) and F4 (Lack of leisure time and negative evaluations). The four PSQ-Org factors also significantly correlated with the full PSQ-Org, with the coefficients ranging from .62 to .87. The PSQ-Org had strongest correlation (.87) with F1 (Poor management and bureaucracy) and the weakest (.62) with F4 (Lack of leisure time and negative evaluations). As there are no negative and non-significant values in the table, we argue that the Bangla version PSQ-Org has convergent validity.

\subsection{Reliability}

\subsubsection{Internal Consistency}

The inter-item correlation matrix of PSQ-Org (Table 1) contained no negative values, indicating that the items were measuring the same characteristic. The reliability of the Bangla version PSQ-Org was further examined by estimating internal consistency. The coefficients of Cronbach's awere calculated. Cronbach's a(standardized) for the Bangla version PSQ-Org was .80. The coefficients for the 'Poor management and bureaucracy', 'Lack of manpower and resources' 'Feelings of excessive duty and being supervised', and 'Lack of leisure time and negative evaluation' dimensions were $.66, .64, .62$, and .57 respectively (Table 2).

\section{Discussion}

The present study was designed to investigate the Factor structure for PSQ-Org in Bangladeshi culture. Analysis of data in EFA demonstrated a four factor model for the PSQ-Org comprising 14 items (6 items dropped; Table 2). Factor 1 (4 items) measures poor management and bureaucracy, Factor 2 (3 items) measures lack of manpower and resources, Factor 3 (4 items) measures feelings of excessive duty and being supervised and Factor 4 (3 items) measures lack of leisure time and negative evaluations. These factors together accounted for $55.14 \%$ of the total variance. The dimension's contribution ranged from $12.72 \%$ to $16.71 \%$ (Table 2). The factors show moderate internal consistency (Cronbach's $\alpha=.57$ to .66 ; Table 2). As shown in Table 3, all the factors were significantly correlated with the whole PSQ-Org $(r=.62$ to.87, $\mathrm{p}<.01)$. The moderate inter-correlations of the factors $(\mathrm{r}=.36$ to. $.58, \mathrm{p}<.01)$ support the representation of the factors as unique, distinguishable components (Jelenchick et al., 2012).

Six items (item 1, 2, 14, 15, 17, \& 19) of the original scale was dropped through item analysis and factor analysis. These items were proved not to be valid in Bangladeshi culture. The items that were dropped in this study include 'dealing with co-workers, the feeling that different rules apply to different people (e.g Favouritism), unequal sharing of work responsibilities, if you are sick or injured youe co-workers seem to look down on you, internal investigations, the need to be accountable for doing your job.' Previous analysis (John M. Shane 2010) has shown six factor solutions for the PSQ-Org with 19 items (item 14: 'unequal sharing of work responsibilities' excluded). As this item is also excluded in the present study, it can be said that this item may not be valid for measuring organizational stress in police population. Why the other five items are not valid in Bangladeshi culture is unknown to the present researcher. Future study can be conducted to clarify this fact.

One important aspect of this study is that it examined the translation validity and convergent validity of the PSQ-Org. Translation validity was assessed through content validity and face validity. Content validity was assesed by Accuracy Index (AI) and Relevance Index (RI). Face validity was assessed by asking the participants six questions on a 2-point scale: yes-no. These questions include whether the questionnaire was readable, logical, clear, comprehensive, answerable and also whether the style \& format of the questions were acceptable. The percentages of 'yes' responses to these questions indicate PSQ-Org's face validity. Convergent validity of the Bangla version PSQ-Org was further examined by estimating inter-factor correlations and the Factor-total correlations (Table 3). Thus the measure has both translation and convergent validity. The coefficients of Cronbach's $\alpha$ were calculated for measuring the internal consistency. Cronbach's $\alpha$ (standardized) for the Bangla version PSQ-Org and its factors indicate its moderate to high internal consistency/ reliability (Table 2).

As with many other studies, this study suffers from a number of limitations, suggesting avenues for future studies. The first limitation is the reliance on a sample of small size. Data from such a small sample might have led to the insufficient reliability (internal consistency) of all the factors of PSQ-Org. Though the minimum sample required for factor analysis was satisfied here future studies on larger samples can increase the reliability coefficients, confirm the factor structure and other psychometric properties of the PSQ-Org in Bangladeshi culture. A second limitation is the use of police officer from Dhaka city only. Such a sample of convenience facilities the early phase of a test construction, but generalizing results to other police officers may not be warranted. Despite these limitations, the present findings can serve as a base of further research on organizational police stress in Bangladesh.

\section{Conclusions}

This study gives us a psychometric tool, the Bangla version PSQ-Org. Further study with larger sample is suggested to confirm the factor structure and validate the present study. 


\section{REFERENCES}

[1] Alexander, C. (1999). Police psychological burnout and trauma. In J.M. Violanti \& D. Paton(Eds.), Police trauma: Psychological aftermath of civilian combat (pp.54-64). Springfield,: Charles C. Thomas.

[2] Anshel, M. H. (2000). A conceptual model and implications for coping with stressful events inpolice work. Criminal Justice and Behavior, 27 (3), 375.

[3] Brown, W. J. (1996). Organization assessment: Determining the state of a police organization. Journal of Police Science and Administration, 14(4), 267-284.

[4] Cattell, R.B., 1966. The scree test for number of factors. Multivariate Behavioral Research 1 (2) 245-276.

[5] Cattell, R.B., 1978. The Scientific Use of Factor Analysis. Plenum, New York.Cooper, C. L., Dewe, P., \& O'Driscoll, M. P. (2001). Organizational stress: A review and critique of theory, research, and applications Sage Publications, Inc.

[6] Cropanzano, R., Rupp, D. E., \& Byrne, Z. S. (2003). The relationship of emotional exhaustion towork attitudes, job performance, and organizational citizenship behaviors. Journal of AppliedPsychology, 88(1), 160-169.

[7] Ellison, K. (2004). Stress and the police officer. New York: Charles C. Thomas, Ltd.Everitt, B.S., 1975. Multivariate analysis: the need for data, and other problems. British Journalof Psychiatry 126, 237-240.

[8] Field, A.P., 2005. Discovering Statistics Using SPSS, 2nd ed. Sage, London.

[9] Gershon, R. (2000). National Institute of Justice. final report: "Project SHIELDS." Washington,DC: National Institute of Justic.

[10] Gershon, R. R., Barocas, B., Canton, A. N., Li, X., \& Vlahov, D. (2009). Mental, physical, and behavioral outcomes associated with perceived work stress in police officers. Criminal Justice and Behavior, 36(3), 275-289.

[11] Gratz, K.L., Roemer, L., 2004. Multidimensional assessment of emotion regulation and dysregulation: development, factor structure, and initial validation of the difficulties in emotion regulation scale. Journal of Psychopathology and Behavioral Assessment 26 (1) 41-54.

[12] Gorsuch, R.L., 1983. Factor Analysis, 2nd ed. Erlbaum, Hillsdale

[13] Guilford, J.P., 1956. Psychometric Methods. McGraw-Hill, New York.

[14] Hart, P. M., Wearing, A. J., \& Headey, B. (1993). Assessing police work experiences: Development of the Police Daily Hassles and Uplifts Scales. Journal of CriminalJustice,21, 553-572.

[15] Hawi, N.S., 2013. Arabic validation of the Internet Addiction Test. Cyber psychology, Behavior and Social Networking $1-5$.

[16] Karim, A. K. M. R., \& Nigar. N.,(2013). The Internet Addiction Test: Assessing itsPsychometric properties in Bangladeshi Culture. Asian journal of Psychiatry (in press)

[17] Kaiser, H.F., 1970. A second generation little jiffy. Psychometrika 35 (4) 401-415.

[18] Kendall, M.G., Stuart, A., 1958. The Advanced Theory of
Statistics. Hafner, New York.

[19] Klockars, C. B., Ivković, S. K., and Haberfeld, M. R. (2006). Enhancing police integrity.Dordrecht, The Netherlands: Springer Verlag.

[20] Kroes, W. H., \& Gould, S. (1979). Job stress in policeman: An empirical study. Police Stress, 1, 9-10.

[21] Kroes, W. H., Hurrell, J. J. Jr., \& Margolis, B. (1974). Job stress in police administration. Journal of Police Science and Administration, 2, 381-387.

[22] Kroes, W. H., Margolis, B., \& Hurrell, J. J. Jr. (1974b). Job stress in policemen. Journal of Police Science and Administration, 2, 145-155.

[23] Kline, P., 1979. Psychometrics and Psychology. Academic Press, London.

[24] Korkeila, J., Kaarlas, S., Ja“a”skeläinen, M., Vahlberg, T., Taiminen, T., 2010. Attached to the web harmful use of the Internet and its correlates. European Psychiatry 25, 236-241.

[25] Kunce, J.T., Cook, D.W., Miller, D.E., 1975. Random variables and correlational overkill. Educational and Psychological Measurement 35 (3) 529-534.

[26] Marascuilo, L.A., Levin, J.R., 1983. Multivariate Statistics in the Social Sciences. Brooks/Cole, Monterey.

[27] McCreary, D. R., \& Thompson, M. M. (2006). Development of two reliable and validmeasures of stressors in policing: The operational and organizational police stressquestionnaires. International Journal of Stress Management, 13(4), 494-518.

[28] Mohren, D. C. L., Swaen, G. M. H., Kant, I. J., van Amelsvoort, L. G. P. M., Borm, P. J.A., \& Galama, J. (2003). Common infections and the role of burnout in a dutchworking population. Journal of Psychosomatic Research, 55(3), 201-208.

[29] Morash, M., Haar, R., \& Kwak, D. (2009). Multilevel influences on police stress. Journal of Contemporary Criminal Justice, 22(1), 26-43.

[30] Muris, P., 2001. A brief questionnaire for measuring self-efficacy in youths. Journal of Psychopathology and Behavioral Assessment 23 (3) 145-149.

[31] Nunnally, J.C., 1978. Psychometric Theory, 2nd ed. McGraw-Hill, New York.

[32] Paton, D., \& Violanti, J. M. (1999). Trauma stress in policing: Issues for future consideration.

[33] Potts, L. W. (1982). Police leadership: Challenges for the eighties. Journal of Police Science and Administration, 10(2), 181-188.

[34] M. Violanti and D. Paton (Eds.), Police trauma: Psychological aftermath of civilian combat(pp. 293-297). Springfield, IL: Charles C. Thomas.

[35] Shane, J. M., (2010). Organizational stressors and police performance. Journal of criminal justice (in press)

[36] Stinchcomb, J. B. (2004). Police stress: Could organizational culture be the culprit.Paperpresented at the Law Enforcement Executive Forum, 4(3) 151-163.Behavior, 16, 196-210.

[37] Taylor, A., \& Benell, C. (2010). Operational and organizational police stress in an Ontario police department: A descriptive study.The Canadian Journal of Police and SecurityServices, 4(4), 223-234. 
[38] Toch, H., Bailey, F. Y., \& Floss, M. (2002). Stress in policing. American PsychologicalAssociation, Washington, DC.

[39] Violanti, J. M., \& Aron, F. (1995). Police stressors: Variations in perceptions among police personnel. Journal of Police Science Administration, 11 (1), 61-75.

[40] Widyanto, L., McMurran, M., 2004. The psychometric properties of the Internet AddictionTest. Cyberpsychology and Behavior 7 (4) 443-450.
[41] Widyanto, L., Griffiths, M.D., Brunsden, V., 2011. A psychometric comparison of the Internet addiction test, the Internet-related problem scale, and self-diagnosis. Cyber psychology, Behavior and Social Networking 14 (3) 141149.

[42] Ursin, H., and Eriksen, H. R. (2004). The cognitive activation theory of stress.Psychoneuroendocrinology, 29(5), 567-592. 